\title{
SIGNIFICADO PROGNÓSTICO DA DEISCÊNCIA E INFECÇÃO DA FERIDA OPERATÓRIA NO CARCINOMA EPIDERMÓIDE DAS VIAS AERODIGESTIVAS SUPERIORES
}

\author{
PROGNOSTIC IMPLICATIONS OF DEHISCENCE AND INFECTION OF \\ OPERATIVE WOUND IN PATIENTS WITH SQUAMOUS CELL CARCINOMA OF \\ UPPER AERODIGESTIVE TRACT
}

\author{
Ali Amar ${ }^{1}$ \\ Lincoln Miyahira ${ }^{2}$ \\ Abrão Rapoport, TCBC-SP ${ }^{3}$ \\ Sérgio Altino Franz ${ }^{4}$
}

\begin{abstract}
RESUMO: Objetivo: Avaliar o efeito da infecção e da deiscência da ferida operatória sobre o controle local do carcinoma epidermóide das vias aerodigestivas superiores, identificando fatores associados à ocorrência destas complicações. Método: Estudo retrospectivo de 239 pacientes com carcinoma epidermóide de boca, orofaringe e hipofaringe tratados cirurgicamente no Departamento de Cirurgia de Cabeça e Pescoço e Otorrinolaringologia do Hospital Heliópolis entre 1990 e 1996, onde foram avaliados o hemograma e o proteinograma pré-operatório em relação ao risco de desenvolvimento de deiscência e infecção da ferida operatória e comparadas as taxas de recidiva local entre os pacientes com e sem deiscência/infecção da ferida operatória. Resultados: A doença em estádio avançado (estádio IV) e a relação albumina/globulina inferior a 1,2 foram mais freqüentes entre os pacientes que desenvolveram deiscência/infecção (DI) da ferida operatória. A taxa de recidiva local foi de $49 \%$ nos pacientes que apresentaram DI e $42 \%$ naqueles sem DI. Conclusão: os pacientes com doença em estádio avançado e aqueles com relação albumina/globulina inferior a 1,2 apresentam maior risco de deiscência/infecção da ferida operatória. A presença de deiscência/infecção não apresentou relação com as taxas de recidiva local.
\end{abstract}

Descritores: Prognóstico; Deiscência da ferida operatória; Infecção da ferida operatória; Carcinoma de células escamosas; Neoplasias de cabeça e pescoço; Cirurgia; Complicações.

\section{INTRODUÇÃO}

A infecção e a deiscência da ferida operatória são complicações graves e ocorrem freqüentemente nos pacientes com carcinoma das vias aerodigestivas superiores, devido à desnutrição e à realização de operações contaminadas ou potencialmente contaminadas. Embora estas complicações tenham menor repercussão sistêmica nos pacientes submetidos a operações da cabeça e pescoço em relação à cavidade torácica e abdominal, pela sua imediata exteriorização, estes eventos retardam a reabilitação e o tratamento irradiante complementar. Além da morbi-mortalidade associada à deiscência e infecção, estas acarretam uma elevação dos custos do tratamento, com o aumento da permanência hospitalar,

1. Mestre em Cirurgia de Cabeça e Pescoço, Hospital Heliópolis, Hosphel, São Paulo.

2. Residente do Departamento de Cirurgia de Cabeça e Pescoço e Otorrinolaringologia do Hospital Heliópolis, Hosphel, São Paulo.

3. Docente Livre em Cirurgia de Cabeça e Pescoço, Hospital Heliópolis, Hosphel, São Paulo.

4. Chefe do Departamento de Oncologia do Hospital Heliópolis, Hosphel, São Paulo.

Trabalho realizado no Departamento de Cirurgia de Cabeça e Pescoço e Otorrinolaringologia do Hospital Heliópolis, Hosphel./SP (Patrocínio da Fundação Oncocentro de São Paulo). 
necessidade de medicamentos e complexidade dos curativos. Apesar dos efeitos deletérios, alguns estudos sugerem que a infecção possa ter alguma influência benéfica no controle local das neoplasias malignas. Em 1906, Coley ${ }^{1}$ relatou a regressão de sarcomas após a inoculação de toxina bacteriana intra-tumoral em uma série de 31 pacientes. Ruckdeschel et al , relataram um aumento da sobrevida em pacientes com carcinoma de pulmão que evoluíram com empiema pleural após a ressecção. Papachristou et $a l^{3}$, em pacientes submetidos a ressecção de melanoma, observou que aqueles que cursaram com infecção da ferida operatória tiveram maior taxa de controle local, embora sem repercussão na sobrevida. Nos pacientes com carcinoma epidermóide das vias aerodigestivas superiores, o significado da infecção da ferida operatória ainda não está estabelecido, com resultados contraditórios nos poucos estudos realiza$\operatorname{dos}^{4-8}$.

Este estudo tem por objetivo avaliar o efeito da infecção e da deiscência da ferida operatória sobre o controle local da doença, identificando fatores associados à ocorrência destas complicações em pacientes com carcinoma epidermóide das vias aerodigestivas superiores.

\section{MÉTODO}

Foram analisados retrospectivamente os prontuários de 239 pacientes com carcinoma epidermóide de boca, orofaringe e hipofaringe. Os pacientes eram virgens de tratamento e foram submetidos à ressecção da lesão primária associada a esvaziamento cervical, com ou sem radioterapia complementar. Foram excluídos 93 pacientes assintomáticos ou que faleceram sem sinais de recidiva local e com seguimento inferior a dois anos, restando 146 pacientes. Quanto ao sexo, 132 eram masculinos e 14 femininos. A idade apresentou média de 54 anos e o sítio primário mais frequiente foi a boca ( 89 casos), seguida da orofaringe ( 35 casos) e da hipofaringe (22 casos).

Foram considerados o estadiamento TNM (UICC/AJCC - 1997), a idade, a realização de transfusão sangüínea peri-operatória e, entre os exames complementares, o hemograma e o proteinograma pré-operatório. O diagnóstico de infecção e/ou deiscência considerou os registros nos prontuários. A deiscência foi caracterizada como abertura da ferida operatória com exposição de planos profundos, com ou sem formação de fístula, não sendo valorizadas as deiscências limitadas à pele como abertura da ferida operatória. A infecção foi definida pela presença de sinais flogísticos (dor, calor local, rubor e edema) e secreção purulenta na ferida operatória. A deiscência e a infecção da ferida operatória foram consideradas conjuntamente.

A análise estatística empregou o teste de quiquadrado com correção de Yates para as variáveis qualitativas. Foram consideradas significativas as diferenças com erro alfa inferior a 5\%.

\section{RESULTADOS}

Entre os 146 pacientes, 57 (39\%) apresentaram deiscência e/ou infecção (DI) da ferida operatória. A idade média foi de 53 anos no grupo com DI, e 54 anos no grupo sem DI. A tabela 1 mostra a distribuição conforme o estádio clínico da doença nos dois grupos (Tabela 1).

No grupo de pacientes com DI, $42(82 \%)$ receberam transfusão sangüínea, com média de 2,8 unidades/paciente, enquanto no grupo sem DI, 54 (71\%) pacientes receberam transfusão, com média de 2,4 unidades/paciente. A contagem linfocitária préoperatória apresentou média de 1960 linfócitos $/ \mathrm{mm}^{3}$ nos pacientes com DI e 2350 linfócitos $/ \mathrm{mm}^{3}$ nos pacientes sem DI.

Entre as variáveis analisadas, a relação albumina/globulina inferior a 1,2 e o estádio clínico IV apresentaram relação com o risco de deiscência e infecção (Tabela 2).

A recidiva no sítio primário foi diagnosticada em 66 (45\%) pacientes. Não houve relação entre a ocorrência de deiscência/infecção da ferida operatória e a recidiva da doença no sítio primário (Tabela 3 ).

Tabela 1 - Estadiamento clínico e ocorrência de deiscência/infecção (DI).

\begin{tabular}{lrrrr}
\hline & \multicolumn{2}{c}{ Com DI } & \multicolumn{2}{c}{ Sem DI } \\
\hline Estádio II & 5 & $(9 \%)$ & 20 & $(23 \%)$ \\
Estádio III & 17 & $(30 \%)$ & 35 & $(39 \%)$ \\
Estádio IV & 35 & $(61 \%)$ & 34 & $(38 \%)$ \\
\hline Total & $57(100 \%)$ & \multicolumn{2}{c}{$89(100 \%)$} \\
\hline
\end{tabular}


Tabela 2 - Fatores de risco para o desenvolvimento de deiscência elou infecção da ferida operatória (análise univariada).

\begin{tabular}{lccl}
\hline Variável & OR & IC $_{\mathbf{9 5 \%}}$ & $\mathbf{p}$ \\
\hline Hb $<13$ g/dL & 1,86 & $0,71-4,87$ & 0,23 \\
Relação A/G $<1,2$ & 2,99 & $1,29-6,97$ & 0,008 \\
Linfócitos < 1800 & 1,45 & $0,64-3,27$ & 0,43 \\
Idade $\geq 55$ anos & 0,96 & $0,46-1,97$ & 0,96 \\
Estádio IV & 2,57 & $1,23-5,41$ & 0,01 \\
Transfusão & 1,90 & $0,74-5,01$ & 0,21 \\
\hline
\end{tabular}

OR - "odds ratio" IC - intervalo de confiança.

$A / G$ - albumina/globulina.

Tabela 3 - Relação entre a presença de deiscêncial infecção da ferida operatória e recidiva local.

\begin{tabular}{lcc}
\hline & \multicolumn{2}{c}{ Recidiva Local } \\
Deiscência/Infecção & SIM & NÃO \\
\hline SIM & $28(49 \%)$ & $29(51 \%)$ \\
NÃO & $38(42 \%)$ & $51(58 \%)$ \\
\hline
\end{tabular}

$p=0,55$

\section{DISCUSSÃO}

A análise conjunta da deiscência e da infecção considerou o fato de que estas complicações geralmente estão associadas. A infecção costuma cursar com deiscência e esta última, por sua vez, está associada a infecção localizada. Não houve diferença significativa nas taxas de controle local entre os grupos com e sem deiscência/infecção (DI). Os resultados ligeiramente piores entre os pacientes com DI refletem o predomínio de pacientes com doença em estádio avançado neste grupo. Um percentual significativo dos pacientes recebeu transfusão sangüínea, um reflexo do grande número de pacientes com doença em estádio avançado submetidos à ressecções extensas, bem como à existência de critérios menos rígidos para indicação de transfusão no período avaliado. A transfusão sangüínea pode estar relacionada a um maior risco de infecção e também a um maior risco de recidiva da doença, embora a magnitude deste efeito ainda não seja conhecida ${ }^{9,10}$. Devido ao efeito imunossupressor do componente leucocitário ${ }^{11}$, é recomendável o uso de sangue deleucotizado (irradiação e/ou filtração) se houver necessidade de transfusão em pacientes com câncer.
A ocorrência de deiscência e infecção também podem retardar o início da radioterapia complementar, comprometendo a sua eficiência, mas este parâmetro não foi avaliado no presente estudo.

Os pacientes com carcinoma das vias aerodigestivas superiores não constituem uma amostra adequada para comprovar o efeito da infecção sobre a recidiva tumoral, considerando a heterogeneidade deste grupo e a multiplicidade de fatores envolvidos na recidiva da doença.

O processo inflamatório desencadeado pela infecção bacteriana poderia destruir as células neoplásicas remanescentes na margem da ressecção, ou mesmo possíveis êmbolos tumorais nas adjacências do tumor, porém não afetaria o desenvolvimento de um segundo tumor. As alterações pré-neoplásicas existentes na mucosa remanescente (campo de cancerização) podem estar relacionadas ao surgimento de um novo tumor, que não pode ser clinicamente distinguido de uma doença residual ao acometer a mesma região anatômica ${ }^{12}$. Por outro lado, a resposta inflamatória pode facilitar o processo de invasão tumoral através da ativação de metaloproteinases, como também estimular a neoangiogênese tumoral mediante a produção de citoquinas pró-inflamatórias ${ }^{13,14}$. Estudos recentes também demonstram a possibilidade de uma resposta paradoxal do sistema imunológico frente às infecções, quando os mediadores inflamatórios podem favorecer o crescimento bacteriano ${ }^{15}$.

As neoplasias malignas causam diminuição dos níveis séricos de albumina, seja por aumento do extravasamento capilar ou por diminuição da síntese hepática associada ao estado catabólico ${ }^{16}$. As globulinas, por sua vez, podem estar aumentadas, causando uma alteração mais pronunciada na relação albumina/globulina nos pacientes com câncer. Um relação $\mathrm{A} / \mathrm{G}$ inferior a 1,2 permitiu identificar os pacientes com maior risco de desenvolverem deiscência ou infecção da ferida operatória. Uma elevação nos níveis séricos das globulinas pode representar uma resposta imunológica ao tumor, mas também está relacionada com a doença de estádio mais avançado.

Pôde-se concluir que a deiscência ou infecção da ferida operatória não apresentam efeito prejudicial sobre o controle local dos carcinomas epidermóides de vias aerodigestivas superiores. A relação albumina/globulina inferior a 1,20 é um fator de risco para ocorrência de deiscência ou infecção da ferida operatória, assim como a presença de doença em estádio clínico avançado. 


\begin{abstract}
Bacground: To evaluate the effect of infection and dehiscence of operative wound in local control of squamous cell carcinoma of upper aerodigestive tract, identifying factors related to these complications. Methods: A retrospective study of 239 patients with squamous cell carcinoma of mouth, oropharynx and hypopharynx treated at Departament of Surgery of Head and Neck Surgery and Otorrinolaringology of Heliópolis Hospital between 1990 and 1996. Preoperative hemogram and proteinogram were evaluated in relation to the risk of dehiscence and infection of the operative wound. The rates of local recurrence were compared among patients with and without dehiscence/infection of the operative wound. Results: Advanced stage disease (stage IV) and albumin/globulin ratio less than 1.2 were more frequent among patients that developed dehiscence/infection (DI) of the operative wound. The rate of local recurrence was $49 \%$ for patients with DI and $42 \%$ for those without DI. Conclusion: Patients with advanced stage disease and those with albumin/globulin ratio less than 1.2 have a higher risk of dehiscence /infection of the operative wound. Dehiscence and/or infection did not demonstrate relationship with local recurrence.
\end{abstract}

Key Words: Prognostic; Dehiscence surgical wound; Infection surgical wound; Carcinoma, squamous cell; Head and Neck neoplasms; Complications; Surgery.

\section{REFERÊNCIAS}

11. Coley WB. Late results of the treatment of inoperable sarcoma by the mixed toxins of erysipelas and Bacilus prodigious. Am J Med Sci, 1906, 131:375-430.

2. Ruckdeschel JC, Codish SD, Stranham A, et al. Postoperative empyema improves survival in lung cancer. Documentation and analysis of natural experiment. N Engl J Med, 1972, 287(20): 1013-1017.

3. Papachristou DN, Fourtner JG - Effect of postoperative wound infection on the course of stage II melanoma. Cancer, 1979, 43(3): 1106-1111.

4. Schantz SP, Skolnik EM, O'Neill JV - Improved survival associated with postoperative wound infection in laryngeal cancer: an analysis of its

therapeutics implications. Otolaryngol Head Neck Surg, 1980, 88(4): 412-417

5. Ramadan HH, Wetmore SJ - Effect of wound infections on head and neck cancer. Arch Otolaryngol Head and Neck Surg, 1992, 118(5): 486-487.

6. Grandis JR, Snyderman CH, Johnson JT, et al. Postoperative wound infection. A poor prognostic sign for patients with head and neck cancer. Cancer, 1992, 70(8): 2166-2170.

7. Jackson RM, Rice DH - Wound infections and recurrence in head and neck cancer . Otolaryngol Head Neck Surg, 1990, 102(4): 331-333.

8. Rodrigo JP, Suárez C - Prognostic significance of postoperative wound infection on head and neck cancer. Otolaryngol Head Neck Surg, 1998, 118(2): 272-275.

9. Sturgis EM, Congdon DJ, Mather FJ, et al. Perioperative transfusion, postoperative infection, and recurrence of head and neck cancer. South Med J, 1997, 90(12):1217-1224.
10. Vamkavas EC, Carven IH - Transfusion of white-cell containing allogeneic blood components and postoperative wound infection: effect of confounding factor. Transfus Med, 1998, 8(1): 29-36.

11. Chu RW - Leucocytes in blood transfusion: adverse effects and their prevention. Hong Kong Med J, 1999, 5(3): 280-284.

12. Slaughter DP, Southwick HW, Smejkal W - Field cancerization in oral stratified squamous epithelium. Cancer, 6: 963-968, 1953.

13. Ferrero E, Fabbri M, Poggi A, et al. - Tumor-driven matrix invasion by infiltrating lymphocytes: involvement of the alpha1 integrin I-domain. Eur J Immunol, 1998, 28(8): 2530-2536.

14. Chen Z, Malhotra PS, Thomas GR, et al. - Expression of proinflammatory and proangiogenic cytokines in patients with head and neck cancer. Clin Cancer Res, 1999, 5(6):1369-1379.

15. Meduri GU - Clinical review. A paradigm shift: the bidirectional effect of inflammation on bacterial growth. Clinical implications for patients with acute respiratory distress syndrome. Crit Care, 2002, 6(1): 24-29.

16. Fleck A, Raines G, Hawker F, et al. - Increased vascular permeability: a major cause of hypoalbuminaemia in disease and injury. Lancet, 1985, 1(8432):781-784.

Endereço para correspondência:

Prof. Dr. Abrão Rapoport

Praça Amadeu Amaral, 47 - cj. 82 - Paraíso

01327-010 - São Paulo - SP

E-mail: cpgcp.hosphel@attglobal.net 